Discussion Paper No. 15-045

The Influence of Collective Action on the Demand for Voluntary Climate

Change Mitigation in Hypothetical and Real Situations

Bodo Sturm and Reinhard Uehleke

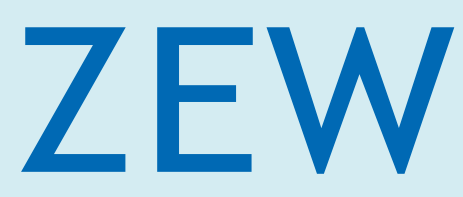

Zentrum für Europäische Wirtschaftsforschung $\mathrm{GmbH}$

Centre for European

Economic Research 
Discussion Paper No. 15-045

\title{
The Influence of Collective Action on the Demand for Voluntary Climate Change Mitigation in Hypothetical and Real Situations
}

\author{
Bodo Sturm and Reinhard Uehleke
}

Download this ZEW Discussion Paper from our ftp server:

http://ftp.zew.de/pub/zew-docs/dp/dp15045.pdf

Die Discussion Papers dienen einer möglichst schnellen Verbreitung von neueren Forschungsarbeiten des ZEW. Die Beiträge liegen in alleiniger Verantwortung der Autoren und stellen nicht notwendigerweise die Meinung des ZEW dar. 


\title{
The Influence of Collective Action on the Demand for Voluntary Climate Change Mitigation in Hypothetical and Real Situations
}

\author{
Bodo Sturm ${ }^{1,2}$ and Reinhard Uehleke ${ }^{1}$ \\ ${ }^{1}$ Leipzig University of Applied Sciences (HTWK), Leipzig \\ ${ }^{2}$ Centre for European Economic Research (ZEW), Mannheim
}

E-mail:

bodo.sturm@htwk-leipzig.de

reinhard.uehleke@gmail.com

\begin{abstract}
:
In this experiment, we investigate determinants of the individual demand for voluntary climate change mitigation. Subjects decide between a cash prize and an allowance from the EU Emissions Trading Scheme for one ton of $\mathrm{CO}_{2}$ that will be deleted afterwards. We vary the incentives of the decision situation in which we distinguish between real monetary incentives and a hypothetical decision situation with and without a cheap talk script. Furthermore, decisions were implemented either as purely individual or as a collective action using majority voting. We observe a significant hypothetical bias in the demand for voluntary climate change mitigation. In case of the individual decision situation this bias is caused solely by subjects with low income. Collective decision making affects demand positively in the hypothetical decision situation only.
\end{abstract}

Keywords: demand for voluntary climate change mitigation, public goods, collective action, hypothetical bias

JEL: Q51, Q54, C93

Acknowledgement: Financial support by the German Federal Ministry of Education and Research (FairPayClim FKZ 01LA1108B) is gratefully acknowledged. We thank workshop participants at the ZEW Mannheim and Carlo Gallier for valuable comments.

Correspondence: Reinhard Uehleke, Leipzig University of Applied Science, Faculty of Business Administration, P.O. 301166, 04251 Leipzig, Germany, reinhard.uehleke@gmail.com 


\section{Introduction}

The question how much people are voluntarily willing to pay in order to mitigate climate change is a rather new topic on the agenda of empirical economists. Recent studies on this issue deliver a quite heterogeneous picture. There are several stated preferences studies (e.g. MacKerron et al. 2009, Achtnicht 2012) that find a relatively high value of Willingness-ToPay (WTP) for voluntary climate change mitigation. Other studies have utilised a revealed preference framework (e.g. Löschel et al. 2013, Diederich and Goeschel 2014a) and in general report much lower WTP values.

One might argue that the stated preferences approach suffers from what has been called the hypothetical bias in the literature (e.g., Murphy et al. 2005) and, hence, leads to rather optimistic WTP estimates. However, due to differences in study design such as question format, subjects' information about the good, framing, subject pool etc., a simple comparison between real and hypothetical WTP for climate change mitigation is difficult. In order to make hypothetical bias responsible for the observed "gap" in WTP, a controlled experimental study is necessary. Another issue lies in the character of the good at stake. Climate change mitigation is a global public good and the values reported in revealed preference WTP studies are usually obtained from a decision framework where individuals face the opportunity to free ride on emissions reductions by others. While the WTP obtained in such a framework is certainly of interest, it is conceivable that the corresponding WTP is higher in a decision framework which, at least partly, excludes the free riding opportunity by introducing some form of collective decision making. For example, the median voting rule has been shown to be a powerful device in order to increase cooperation in social dilemma situations (e.g. Walker et al. 2000, Bernard et al. 2013, Hauser et al. 2014).

The objective of this paper is to investigate the magnitude of hypothetical bias in the voluntary demand for the global public good climate change mitigation and whether a 
collective action within a small group of subjects can increase this demand. For this purpose we run a web-based experiment. Participants chose between a cash price in Euro and a European Union Allowance (EUA) which would be deleted after the experiment. From the observed demand the WTP is derived. This basic design was first used by Diederich and Goeschl (2014a) and here it is implemented both with real monetary incentives and as a purely hypothetical decision situation. Furthermore, we introduced a collective action in which the group $(n=100)$ voted whether all members purchased the offered EUAs or received the cash price.

We find a rather small but statistically significant hypothetical bias in the demand for voluntary climate change mitigation. Hypothetical bias defined as the ratio of hypothetical to real WTP amounts to 1.15 for the individual decision situation and 1.20 in case of collective action. The observed real WTP for voluntary climate change mitigation is about $17 €$ per $\mathrm{tCO}_{2}$. Collective action increases voluntary demand for climate change mitigation in a hypothetical decision situation, but does not affect choice if subjects face real monetary incentives.

The remainder of the paper is organized as follows: Section 2 provides an overview of the related literature. Section 3 describes the sample and the experimental design and Section 4 derives our theoretical predictions. We present the experimental results in Section 5 and Section 6 concludes the paper.

\section{Related literature}

There are at least three branches of literature directly related to our study - both from the perspective of voluntary demand for climate change mitigation as well as from a methodological point of view. At first are the several stated preferences studies which have recently explored the question of demand for voluntary climate change mitigation and derived WTP for climate change mitigation in monetary units per $\mathrm{tCO}_{2}{ }^{1}$ Brouwer et al. (2008) asked airport passengers for their WTP to offset $\mathrm{CO}_{2}$ emissions caused by their flights. Mean WTP 
for the reduction of one $\mathrm{tCO}_{2}$ across all passengers amounted to $25 €$, with a remarkable geographical variation: Mean WTP for Asian travellers was found to be the lowest at a value of $10 € / \mathrm{tCO}_{2}$ while European participants were recorded as willing to pay a mean value of $41 € / \mathrm{tCO}_{2}$. In a similar study MacKerron et al. (2009) estimated WTP for offsetting $\mathrm{CO}_{2}$ emissions of a hypothetical flight from New York to London to be approximately $28 € / \mathrm{tCO}_{2}$. Achtnicht (2012) measured the WTP for the reduction of $\mathrm{CO}_{2}$ emissions using data from interviews with potential car-buyers across Germany. The interviewees were presented with a stated preference choice experiment consisting of hypothetical car types that differed in various characteristics such as price, propulsion technologies, fuel type, and $\mathrm{CO}_{2}$ emissions. Achtnicht estimated a median WTP for the reference group which resulted in a range of $89 €$ to $256 € / \mathrm{tCO}_{2}$, significantly higher than the aforementioned estimates. In a recent paper, Blasch and Farsi (2014) reported on survey data pertaining to the mean WTP for voluntary carbon offsets in the range of $0.75 € / \mathrm{tCO}_{2}$ to $€ 16.60 € / \mathrm{tCO}_{2}$ depending on the emission activity.

Second, there are the relatively few studies that attempt to elicit the real demand for voluntary climate change mitigation from a purely individual perspective. Löschel et al. (2013) sold EUAs at different prices to a sample of 202 subjects from the Mannheim, Germany population. A median WTP of zero and a mean WTP of $12 € / \mathrm{tCO}_{2}$ were found. A similar framed field experiment with cash incentives was conducted by Diederich and Goeschl (2014a) who determined the willingness to abate one $\mathrm{tCO}_{2}$ among the German Internet-using population. In their design, 2,440 participants faced a real trade-off between a cash prize and guaranteed emissions reductions through the retirement of EUAs. They estimated a zero median WTP and a mean WTP of about $6 € / \mathrm{tCO}_{2}$.

Comparisons of the two different approaches show that in general the revealed preferences studies result in lower demand for voluntary climate change mitigation and therefore in lower values for WTP. One potential reason for this difference is that the stated preferences 
approach suffers from what has been called the hypothetical bias in the literature and, hence, leads to rather optimistic estimates for the demand for voluntary climate change mitigation and derived WTP values. The existence of hypothetical bias in the demand for private and public goods has been shown in a variety of decision situations (Blumenschein et al. 2008, Cummings et al. 1995, 1997) and in a meta-analysis of the hypothetical bias Murphy et al. (2005) report a median ratio of hypothetical WTP to actual value of 1.35.

The cheap talk script has been suggested as a device to reduce or even eliminate hypothetical bias (Cummings and Taylor 1999, Landry and List 2007). The effect of cheap talk is, however, ambiguous in the literature. While some studies find that hypothetical bias is reduced (Aadland and Caplan 2003, Brown et al. 2003, Champ at al. 2009, Moser et al. 2014) other studies find no effect of cheap talk (Blumenschein et al. 2008) or that it even exacerbates hypothetical bias (Morrison and Brown 2009, Aadland and Caplan 2006). Finally, List (2001) shows that cheap talk is only effective for subjects with little experience in the market.

The third branch of literature consists of experimental studies that determine the effect of voting institutions in social dilemma situations. Walker et al. (2000) and Margreiter et al. (2005) report that group members cooperate more in a common-pool resource experiment under enforced voting rules compared to a no-vote scheme. Kroll et al. (2007) and Kosfeld et al. (2009) estimated the effect of different voting mechanisms on the level of contributions to a public good and found that a binding vote significantly increases overall contributions. Thus, a collective action is able to increase cooperation in social dilemma situations - at least if the result of the collective action is binding to all subjects of the group. The theoretical argument behind this observation is rather simple (e.g. Bernard et al. 2013). Since free-riding within the group is prevented, there is no longer a unique Nash equilibrium of complete freeriding. For instance, if all subjects vote for the cooperative solution, the majority decision will 
not change when a single subject changes her decision. This means that also full contributions to a public good constitute an equilibrium which payoff-dominates all other equilibria including the zero contribution equilibrium. Additionally, Bernard et al. (2013) and Hauser et al. (2014) consider situations where the effect of the collective action is limited to a subgroup of subjects only and find that if players vote in subgroups only, there is less over-extraction than if contributions are determined individually. In one of our treatments, a binding collective action into the determination of the contribution to the public good is also implemented. In our case, however, the subgroup $(n=100)$ is extremely small in relation to the overall population. In a similar framed field experiment Löschel et al. (2014) implemented a collective action into the decision of an even smaller group $(n=32)$ and found that the probability of purchasing EUAs is higher in the treatment with collective action compared to the treatment with individual action. Additionally to their study, we investigate the collective action effect for a hypothetical and real decision situation and for a larger group.

\section{Sample and experimental design}

Between $21^{\text {th }}$ and $28^{\text {th }}$ of July 2014 we drew an internet sample of 3,103 subjects from the German voting population. The participants are between 18 and 66 years old and are more likely to hold an academic degree than the general population as depicted in Table 1 . The survey was conducted by the internet survey provider YOUGOV and participants were enumerated with bonus points equivalent to $60 €$ cent.

Table 1: Basic demographics

\begin{tabular}{lcc}
\hline \hline Demographic characteristic & Sample & Population aged 18 - 66 \\
\hline Male & $51 \%$ & $50 \%$ \\
Mean Age & 43 & 43 \\
Academic degree & $23 \%$ & $18 \%$ \\
\hline \hline
\end{tabular}


We gave participants the possibility to choose between a cash award and a certificate from the EU Emission Trading System (EU ETS) about one ton of $\mathrm{CO}_{2}$, which we then bought and deleted. Thus, respondents decided between a cash award and the reduction of one ton of $\mathrm{CO}_{2}$ emissions by deletion of one European Emission Allowance (EUA). This reduction can be seen as a voluntary contribution to a global public good in which the cash award represents the opportunity costs of this decision. Therefore, the individual WTP for voluntary climate change mitigation is at least the cash award if the subject choses the certificate.

Each participant was randomly allocated to one of the following treatments: One treatment with real payoffs and real emission reductions ("REAL") and two hypothetical treatments ("HYPO”), one with cheap talk (“CT") and one without cheap talk ("nCT"). All treatments were conducted in an individual setting ("Ind") and a collective setting ("Coll"). In the collective setting the individual contribution was replaced by a group contribution, where all group members received the majority choice. Table 2 presents the resulting number of respondents in the three by two split sample design.

Table 2: Number of respondents in each treatment

\begin{tabular}{lll}
\hline \hline \# Respondents (Treatment) & Individual (Ind) & Collective (Coll) \\
\hline REAL & 516 (REAL_Ind) & 519 (REAL_Coll) \\
Hypothetical (HYPO) with Cheap Talk (CT) & 519 (HYPO_Ind_CT) & 514 (HYPO_Coll_CT) \\
Hypothetical (HYPO) without Cheap Talk (nCT) & 513 (HYPO_Ind_nCT) & 522 (HYPO_Coll_nCT) \\
\hline \hline
\end{tabular}

Cash awards or prices for the certificate varied from $2 €$ to $30 €$ and were randomly assigned to the participant. Each participant was allocated to one of five price groups and asked three times about her choice with three different prices. Table 3 shows the price groups and prices. We chose this particular design, because this way it was possible to ensure equal group sizes 
for the Coll treatment at the price level. We drew one group out of the five and realized one of the three decisions. Thus, a participant had a one to five chance to be in the winning group. Expected payoff for Ind with approximately 100 subjects in each group equals $1,600 €$ if everybody takes the cash award. In Coll it is not possible to calculate the expected payoff as there is only one draw that must be realized for $1 / 5^{\text {th }}$ of the respondents. In the most expensive case $(3,000 €)$ we would randomly draw a price of $30 €$ and pay out the price for 100 subjects if the majority decides to take the cash award.

Table 3: Price groups and prices

\begin{tabular}{lccc}
\hline \hline Price group & $\mathrm{P}_{\text {low }}$ & $\mathrm{P}_{\text {middle }}$ & $\mathrm{P}_{\text {high }}$ \\
\hline I & 2 & 8 & 14 \\
II & 6 & 12 & 18 \\
III & 10 & 16 & 22 \\
IV & 14 & 20 & 26 \\
V & 18 & 24 & 30 \\
\hline \hline
\end{tabular}

Before the decision screen, we gave participants information about the EU ETS, explaining the principle and scope of emission trading. The information screen was followed by an instruction screen that explained the rules and included an example for the decision. Translation of the information screen is given in Annex A1 and the instructions for the REAL_Ind and REAL_Coll groups are given in Annex A2 and A3. The hypothetical treatments vary only in that the wording was adapted to reflect a hypothetical situation. The cheap talk script is reproduced in Annex A4.

\section{Hypotheses}

Although the marginal benefit of a contribution to the global public good climate change is zero while marginal costs are positive, there is ample empirical evidence from previous revealed preferences studies (Diederich and Goeschl 2014a, Löschel et al. 2013) and the 
literature on donations (e.g. Andreoni 1990), that shows that contributions are not zero as predicted by standard economic theory based on selfishness. On the one hand, positive contributions can be explained by moral motivations, which are associated with contributing to the public good itself rather than with the effect of the contribution (Cooper et al. 2004). For example, subjects could receive a warm glow of giving (Crumpler and Grossman 2008), could buy moral satisfaction instead of ascribing an economic value to the public good (Kahneman and Knetsch 1992), gain from a positive self-image (Johansson-Stenman and Svedsäter 2010), or follow deontological decision rules that cause them to disregard consequences and instead decide on the basis of morally mandated duties to do the right thing (Spash 2006). On the other hand, it is possible that some subjects are willing to contribute only under the condition that others also do so (e.g. Sugden 1984, Fischbacher et al. 2001). Since in REAL all decisions are individual, only those conditionally cooperative subjects who expect that others will also "bear their share" should contribute. However, since free-riding within the group is possible strong incentives exist to understate the demand for the public good.

Our design, in particular, allows us to test three hypotheses about the voluntary contribution to climate change mitigation.

\section{1) The effect of cheap talk}

Since the effect of cheap talk is ambiguous in the literature, we test whether cheap talk is effective in a framed field experiment about the voluntary demand for a global public good. We test the following hypothesis regarding the proportion of subjects who choose the certificate, $p^{\text {cert }}$ : 


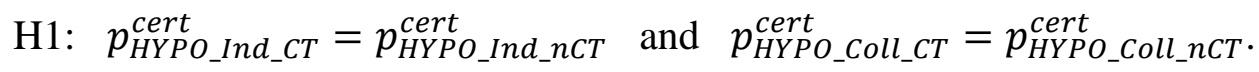

\section{2) The effect of the hypothetical decision situation}

The existence of hypothetical bias, i.e. higher demand for the good when preferences are stated instead of being revealed, has been shown in a variety of decision situations. However, as presented in the literature review, there is some evidence that by means of a cheap talk script the bias can be eliminated or at least reduced. Therefore, we derive the following hypothesis:

$\mathrm{H} 2: p_{R E A L_{-} I n d}^{\text {cert }}=p_{\text {HYPO_Ind_CT }}^{\text {cert }}$ and $p_{R E A L_{-} C o l l}^{\text {cert }}=p_{H Y P O_{-} C o l l_{-} C T}^{\text {cert }}{ }^{2}$

\section{3) The impact of collective action}

The effect of purchasing certificates on German or even global $\mathrm{CO}_{2}$ emissions in our experiment is negligible - even if all members of a group $(n=100)$ chose the certificate. Therefore under standard theory we expect zero contributions and no effect of the collective action. However, taking into account the empirical evidence on voluntary contributions positive contributions can be expected. Furthermore, in a collective action treatment incentives to contribute to the public good change. On the one hand, since free-riding within the group is prevented, there is no longer a unique Nash equilibrium of complete free-riding and full contributions to the public good also constitute an equilibrium (Bernard et al. 2013). Yet in our case subjects do not perceive a monetary payoff from the global public good and the full contribution equilibrium is payoff dominated by the zero contribution equilibrium, hence it should not be observed. On the other hand, since all subjects have to contribute the same amount, subjects who tend to follow the strategy of a conditional co-operator in comparison to REAL have an additional incentive to cooperate in Coll. They are assured that 
everybody in the group makes the same contribution, which makes them contribute more than in Ind. Thus, from this perspective contributions can be expected to be higher in Coll than in Ind. Therefore, our last hypothesis is:

$\mathrm{H} 3: p_{R E A L_{-} I n d}^{\text {cert }}=p_{R E A L_{-} C o l l}^{\text {cert }}$ and $p_{H Y P O_{-} I n d_{-} C T}^{\text {cert }}=p_{H Y P O_{-} \text {Coll_CT }}^{\text {cert }}$.

\section{Results}

For each of the two REAL treatments a price vector and one of the three decisions (prices) were randomly selected. For REAL_Ind, the price of $22 €$ and for REAL_Coll the price of $14 €$ was chosen. In REAL_Ind at this price out of 105 participants 47 chose the cash award and 58 the certificate. In REAL_Coll the majority chose the certificate (50 to 54) and everyone in the group received a certificate for deletion. Therefore 47 participants received the $22 €$ cash award and 162 EU ETS allowances were bought and deleted. ${ }^{34}$

\subsection{Univariate tests of hypotheses}

In this section our hypotheses are tested with a test for the equality of proportions. Therefore we calculate the share of buyers of certificates, $p^{\text {cert }}$, in each treatment. Because we have three observations per subject we additionally test each price-quantity combination individually.

\section{1) The effect of cheap talk}

Figure 1 shows the demand curves for the groups with and without cheap talk. On the left side the demand for the individual treatment is presented and on the right side for the collective action treatment. The demand curves are not decreasing monotonically, but the fitted values show that there is a clear downwards trend with increasing price. The difference in shares 
between treatments is low and the demand curves are overlapping for many prices, suggesting that cheap talk has no effect on demand.

Figure 1: Demand curves for Cheap Talk vs. no Cheap Talk by Ind and Coll

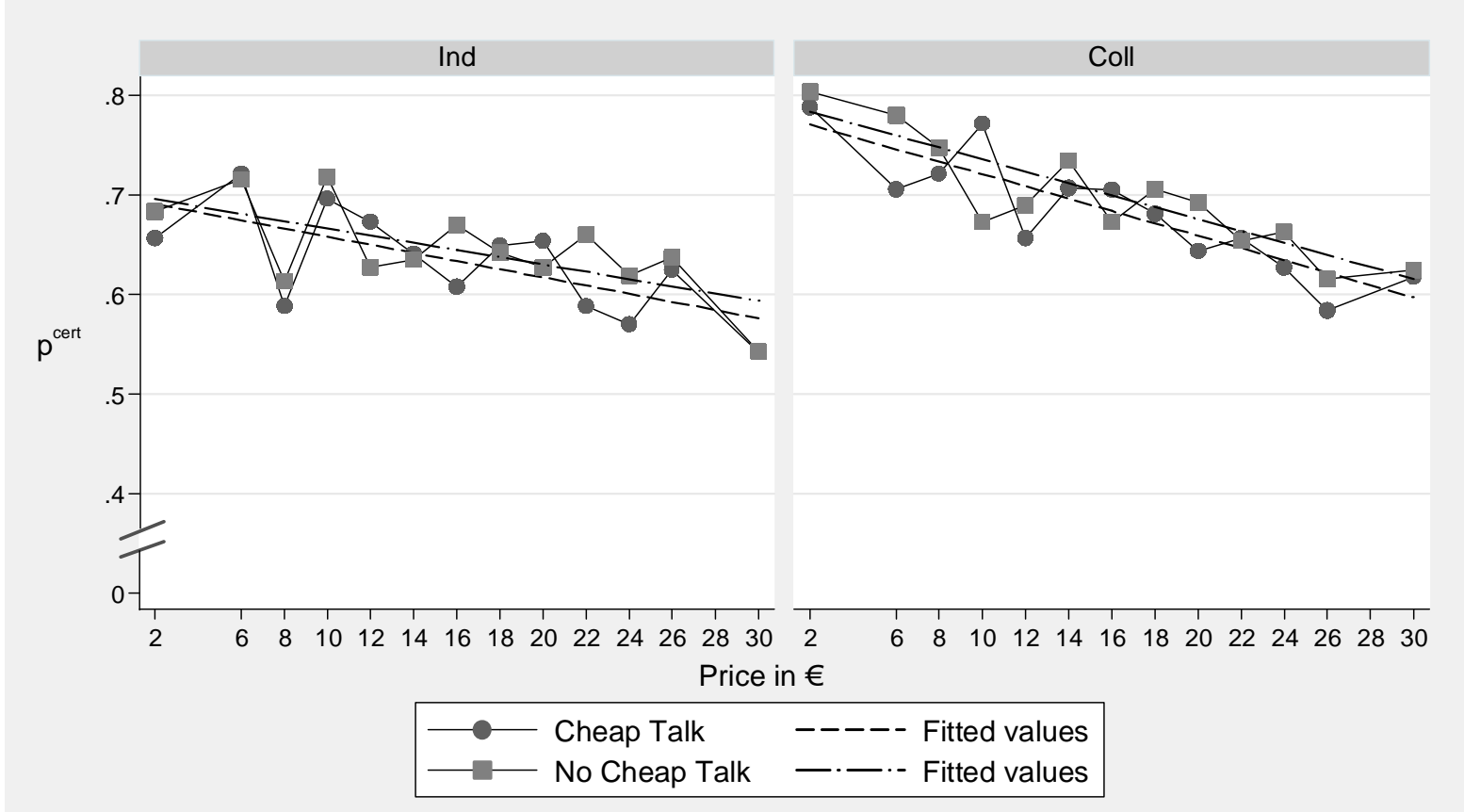

We can test for an effect of cheap talk with a test for equality in proportions, which is summarized in Table 4. The table shows the shares of buyers of certificates - for all prices and for the individual price levels (low, middle and high). This way, each observation is used only once in the tests at the individual price level. All tests fail to reject the hypothesis $\mathrm{H} 1$ of no effect of cheap talk. 
Table 4: Test for equality proportions for the effect of cheap talk

\begin{tabular}{|c|c|c|c|c|c|c|c|c|c|c|}
\hline & \multicolumn{5}{|c|}{ Ind } & \multicolumn{5}{|c|}{ Coll } \\
\hline & $\begin{array}{c}\text { HYPO } \\
\text { CT }\end{array}$ & $\mathrm{n}$ & $\begin{array}{c}\text { HYPO } \\
\text { nCT }\end{array}$ & $\mathrm{n}$ & $\mathrm{P}>|\mathrm{z}|$ & $\begin{array}{c}\text { HYPO } \\
\text { _CT }\end{array}$ & $\mathrm{n}$ & $\begin{array}{c}\text { HYPO } \\
\text { nCT }\end{array}$ & $\mathrm{n}$ & $\mathrm{P}>|\mathrm{z}|$ \\
\hline Total & 0.63 & 1557 & 0.64 & 1539 & 0.513 & 0.68 & 1542 & 0.70 & 1566 & 0.343 \\
\hline \multicolumn{11}{|l|}{ By price } \\
\hline low (1st) & 0.70 & 519 & 0.70 & 513 & 0.936 & 0.73 & 514 & 0.74 & 522 & 0.772 \\
\hline middle (2nd) & 0.62 & 519 & 0.63 & 513 & 0.664 & 0.67 & 514 & 0.69 & 522 & 0.441 \\
\hline high (3rd) & 0.58 & 519 & 0.60 & 513 & 0.544 & 0.65 & 514 & 0.67 & 522 & 0.567 \\
\hline
\end{tabular}

\section{2) The effect of the hypothetical decision situation}

Figure 2 shows the demand curves and fitted values for the REAL and HYPO treatments (with cheap talk). Hypothetical bias seems to be present and increasing with price in Ind, whereas in Coll bias seems to decrease with price.

Figure 2: Demand Curves for REAL vs. HYPO

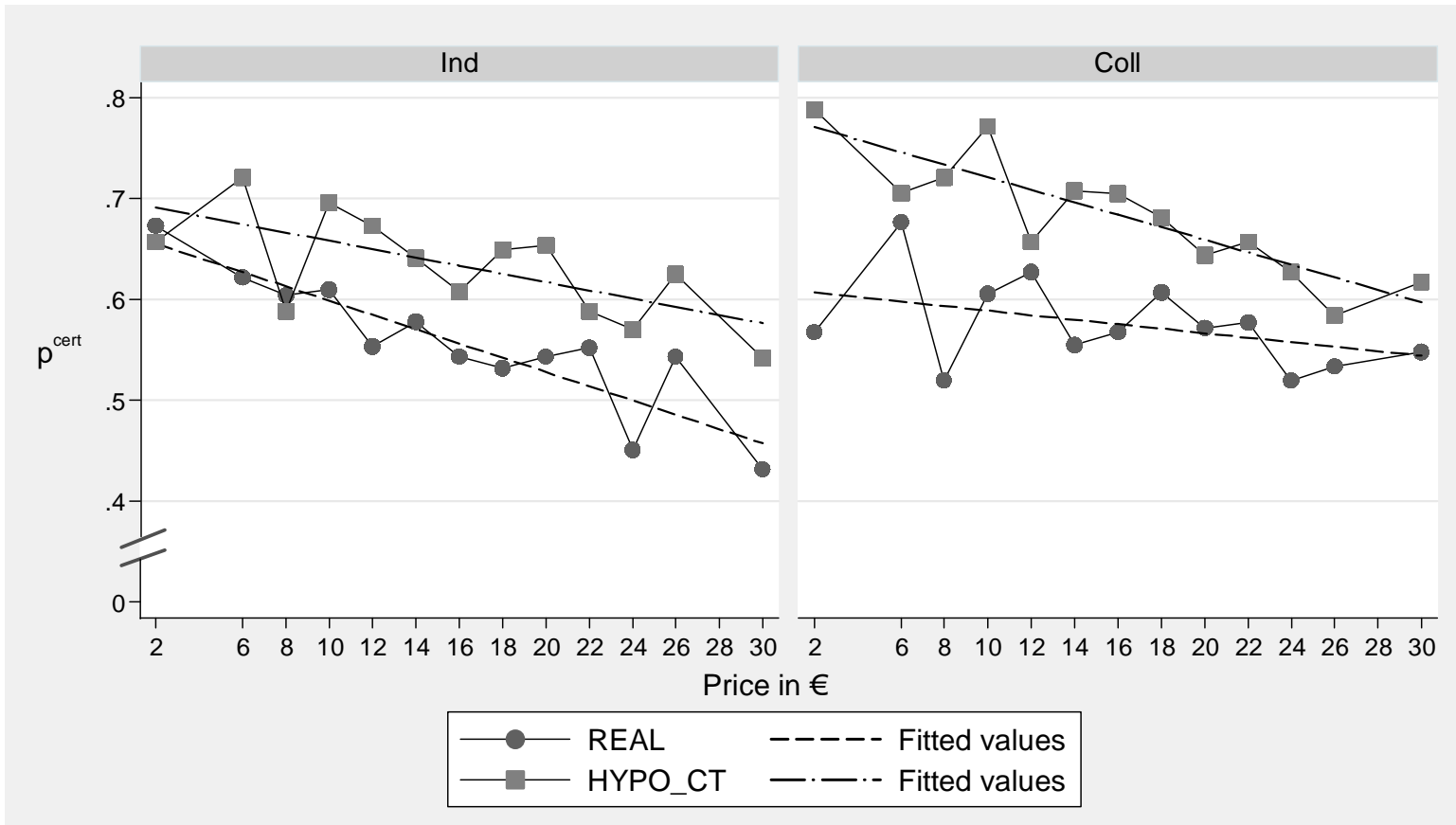


Table 5 presents the test for the presence of hypothetical bias. We can reject the hypothesis $\mathrm{H} 2$ of no hypothetical bias with high confidence, whether observations are pooled or at the level of each single decision. Overall we find a bias of 8 (Ind) to 11 (Coll) percentage points on the demand for certificates.

Table 5: Test for equality proportions for the hypothetical bias

\begin{tabular}{|c|c|c|c|c|c|c|c|c|c|c|}
\hline & \multicolumn{5}{|c|}{ Ind } & \multicolumn{5}{|c|}{ Coll } \\
\hline & REAL & $\mathrm{n}$ & $\begin{array}{c}\text { HYPO } \\
\text { _CT }\end{array}$ & $\mathrm{n}$ & $\mathrm{P}>|\mathrm{z}|$ & REAL & $\mathrm{n}$ & $\begin{array}{c}\text { HYPO } \\
\text { _CT }\end{array}$ & $\mathrm{n}$ & $\mathrm{P}>|\mathrm{z}|$ \\
\hline Total & 0.56 & 1548 & 0.63 & 1557 & 0.000 & 0.58 & 1557 & 0.68 & 1542 & 0.000 \\
\hline By price & & & & & & & & & & \\
\hline low (1st) & 0.62 & 516 & 0.70 & 519 & 0.007 & 0.62 & 519 & 0.73 & 514 & 0.000 \\
\hline middle (2nd) & 0.54 & 516 & 0.62 & 519 & 0.009 & 0.56 & 519 & 0.67 & 514 & 0.000 \\
\hline high (3rd) & 0.51 & 516 & 0.59 & 519 & 0.020 & 0.55 & 519 & 0.65 & 514 & 0.002 \\
\hline
\end{tabular}

\section{3) The impact of collective action}

Figure 3 shows the influence of collective decision making on the demand for certificates for REAL (left) and HYPO_CT (right). The demand curves seem to overlap with real transaction but in a hypothetical decision situation, demand seems to be larger for many bidding points. 


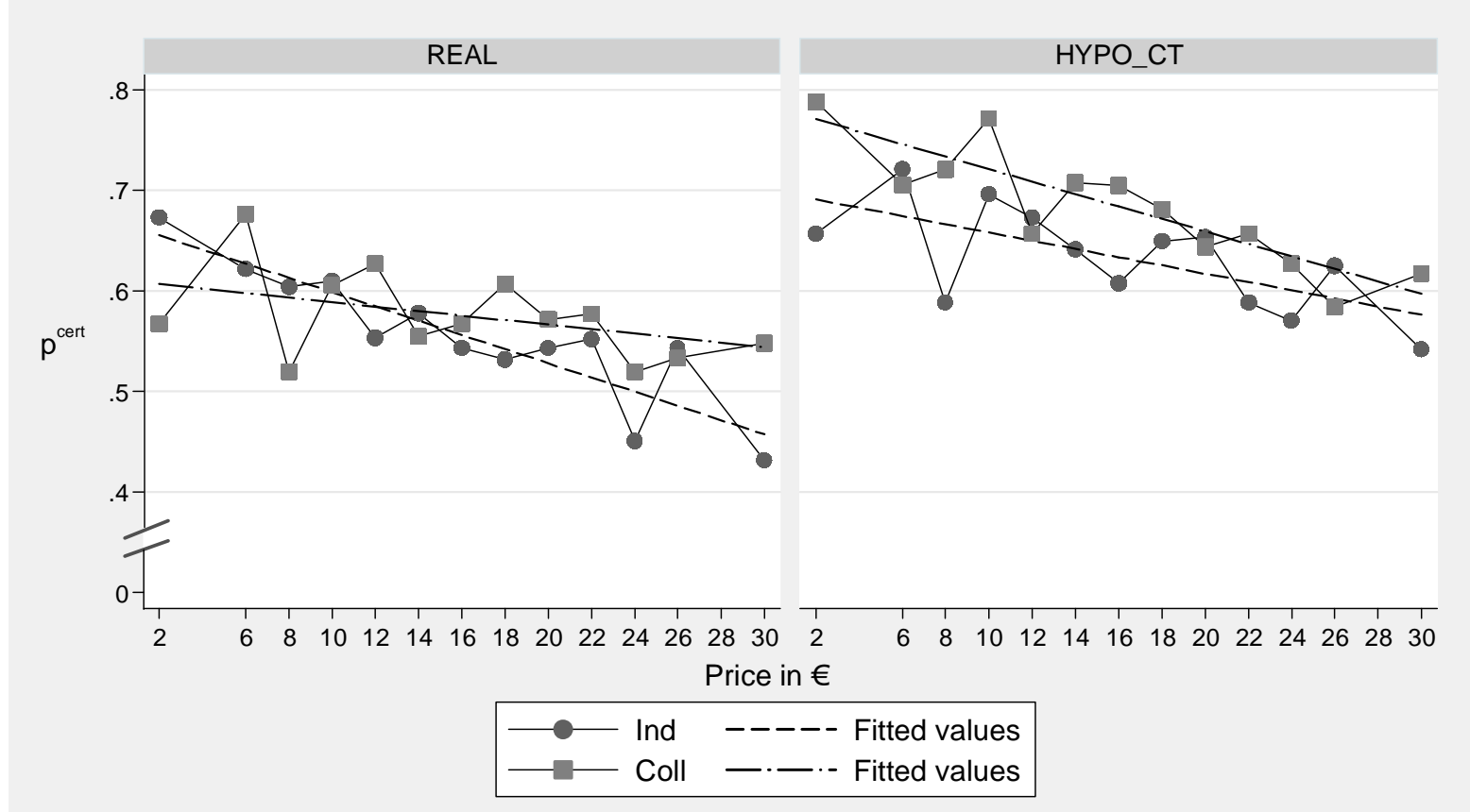

Table 6 gives the test results for differences in proportions for all observations and by price. In REAL we cannot reject the hypothesis $\mathrm{H} 3$ of no influence of collective decision making, but in HYPO we can reject the null hypotheses overall and for the second and third prices.

Table 6: Test for equality of proportions for the influence of collective action

\begin{tabular}{|c|c|c|c|c|c|c|c|c|c|c|}
\hline & \multicolumn{5}{|c|}{ REAL } & \multicolumn{5}{|c|}{ " HYPO_CT } \\
\hline & Ind & $\mathrm{n}$ & Coll & $\mathrm{n}$ & $\mathrm{P}>|\mathrm{z}|$ & Ind & $\mathrm{n}$ & Coll & $\mathrm{n}$ & $\mathrm{P}>|\mathrm{z}|$ \\
\hline Total & 0.56 & 1548 & 0.58 & 1557 & 0.279 & 0.63 & 1557 & 0.68 & 1542 & 0.003 \\
\hline \multicolumn{11}{|l|}{ By price } \\
\hline low (1st) & 0.62 & 516 & 0.62 & 519 & 0.957 & 0.70 & 519 & 0.73 & 514 & 0.178 \\
\hline middle (2nd) & 0.54 & 516 & 0.56 & 519 & 0.478 & 0.62 & 519 & 0.67 & 514 & 0.077 \\
\hline high (3rd) & 0.51 & 519 & 0.55 & 519 & 0.227 & 0.59 & 519 & 0.65 & 514 & 0.040 \\
\hline
\end{tabular}

To sum up, the univariate tests of our hypotheses show that there is no effect of cheap talk, that hypothetical bias is present and that collective decision making changes demand only in 
the hypothetical treatment. Because there is no effect of cheap talk we will pool the hypothetical treatments from now on and discuss the pooled results.

\subsection{Willingness to pay (WTP) for the abatement of one ton of $\mathrm{CO}_{2}$}

One non-parametric estimator for the WTP from dichotomous responses is the lower bound Turnbull (LBT) estimator (Haab and McConnel 2003). Table 7 shows the Turnbull WTP for each treatment.

Table 7: Lower bound Turnbull and median WTP

\begin{tabular}{lccc}
\hline \hline in $€$ & WTP & SD & Median \\
\hline REAL_Ind & 16.15 & 0.48 & $22-30$ \\
REAL_Coll & 13.79 & 0.32 & $>30$ \\
HYPO_Ind & 18.77 & 0.36 & $>30$ \\
HYPO_Coll & 18.15 & 0.25 & $>30$ \\
\hline \hline
\end{tabular}

At first it stands out that WTP in REAL_Coll is lower than in the corresponding Ind treatment, which is opposed to our hypotheses and incoherent with the scatterplots in Figure 3, which indicate that the shares of certificates are higher in the Coll treatment for most of the offered cash prices. This result demonstrates that sometimes the Turnbull WTP cannot be calculated consistently over several treatments if demand is not decreasing monotonously. The reason is that differences in WTP are artificially generated by asymmetries in the cellpooling procedure, in particular if the last cost category is pooled in only one treatment group as the following example of our data shows. Table 8 shows the complete calculation for the Turnbull WTP for the REAL treatments according to the instructions in Annex B1. $\mathrm{WTP}_{\mathrm{REAL} \_ \text {Ind }}$ is $16.15 €$ and WTP $\mathrm{REAL} \_$Coll $_{\text {is }} 13.79 €$. To test for differences in the lower bound 
Turnbull WTP a t-test can be employed. ${ }^{5}$ With a t-value of 4.05 we find that the difference is significant at the $1 \%$ level.

This difference, however, is sensitive to small changes in the dataset. If one leaves out five observations that chose a certificate for the highest price, WTP should decrease, because the share of subjects that choose the cash amount increases. Instead $\mathrm{WTP}_{\mathrm{REAL} \_ \text {Coll }}$ is increasing by $3 €$ to $16.92 €$ (as shown in Annex B2) and the difference to WTP $\mathrm{REAL}_{-}$Ind disappears. The new t-value is 1.12 and therefore we cannot the reject the hypotheses of equal average WTP in these two treatments. This example shows that a comparison of Turnbull WTP can lead to erroneous conclusions about treatment effects. To circumvent this problem we use an alternative smoothing method.

Table 8: Turnbull WTP for REAL_Ind and REAL_Coll

\begin{tabular}{|c|c|c|c|c|c|c|c|c|c|c|c|c|c|c|c|}
\hline \multicolumn{8}{|c|}{ Lower Bound Turnbull for REAL_Ind } & \multicolumn{8}{|c|}{ Lower Bound Turnbull for REAL_Coll } \\
\hline $\mathrm{tj}$ & $\mathrm{N}_{\mathrm{i}}$ & $\mathrm{T}_{\mathrm{i}}$ & $\mathrm{F}_{\mathrm{i}}$ & $\mathrm{F}_{\mathrm{i}}^{*}$ & $f_{i}^{*}$ & $\mathrm{E}_{\mathrm{LB}}$ & $\mathrm{V}\left(\mathrm{E}_{\mathrm{LB}}\right)$ & $\mathrm{tj}$ & $\mathrm{N}_{\mathrm{i}}$ & $\mathrm{T}_{\mathrm{i}}$ & $\mathrm{F}_{\mathrm{i}}$ & $\mathrm{F}_{\mathrm{i}}^{*}$ & $\mathrm{f}_{\mathrm{i}}^{*}$ & $\mathrm{E}_{\mathrm{LB}}$ & $\mathrm{V}\left(\mathrm{E}_{\mathrm{LB}}\right)$ \\
\hline 2 & 33 & 101 & 0.33 & 0.33 & 0.33 & 0.00 & 0.01 & 2 & 45 & 104 & 0.43 & 0.38 & 0.38 & 0.00 & 0.00 \\
\hline 6 & 39 & 103 & 0.38 & 0.38 & 0.05 & 0.10 & 0.0 & 6 & 33 & 102 & 0.32 & p.b. & & & \\
\hline 8 & 40 & 101 & 0.40 & 0.39 & 0.01 & 0.09 & 0.00 & 8 & 50 & 104 & 0.48 & 0.42 & 0.04 & 0.07 & 0.03 \\
\hline 10 & 41 & 105 & 0.39 & p.b. & & & & 10 & 41 & 104 & 0.39 & p.b. & & & \\
\hline 12 & 46 & 103 & 0.45 & 0.43 & 0.04 & 0.30 & 0.01 & 12 & 38 & 102 & 0.37 & p.b. & & & \\
\hline 14 & 87 & 206 & 0.42 & p.b. & & & & 14 & 93 & 209 & 0.44 & 0.42 & 0.01 & 0.05 & 0.02 \\
\hline 16 & 48 & 105 & 0.46 & 0.46 & 0.03 & 0.32 & 0.04 & 16 & 45 & 104 & 0.43 & p.b. & & & \\
\hline 18 & 96 & 205 & 0.47 & 0.46 & 0.00 & 0.05 & 0.00 & 18 & 81 & 206 & 0.39 & p.b. & & & \\
\hline 20 & 48 & 105 & 0.46 & p.b. & & & & 20 & 45 & 105 & 0.43 & 0.43 & 0.00 & 0.05 & 0.08 \\
\hline 22 & 47 & 105 & 0.45 & p.b. & & & & 22 & 44 & 104 & 0.42 & p.b. & & & \\
\hline 24 & 56 & 102 & 0.55 & 0.50 & 0.04 & 0.76 & 0.00 & 24 & 50 & 104 & 0.48 & 0.47 & 0.04 & 0.81 & 0.01 \\
\hline 26 & 48 & 105 & 0.46 & p.b. & & & & 26 & 49 & 105 & 0.47 & p.b. & & & \\
\hline 30 & 58 & 102 & 0.57 & 0.57 & 0.07 & 1.59 & 0.09 & 30 & 47 & 104 & 0.45 & p.b. & & & \\
\hline $30+$ & & & & 1 & 0.43 & 12.94 & & $30+$ & & & & 1 & 0.53 & 12.81 & \\
\hline Low & $\mathrm{rB}$ & $n$ & $\overline{\mathrm{rn}}$ & & & 16.15 & 0.23 & Low & er B & ind & Irn & & & 13.79 & 0.1 \\
\hline
\end{tabular}

A less susceptible quantity adjustment is to calculate the no-shares of a fitted demand curve and calculate the Turnbull WTP on the basis of these fitted shares, which results in a WTP $\mathrm{REAL} \_$Ind $_{\text {of }} 16.64 €$ and $\mathrm{WTP}_{\mathrm{REAL} \_ \text {Coll }}$ of $17.23 € .^{6}$ In accordance with the line and scatterplots in Figure 3, WTP is slightly higher in the Coll treatment, but the difference is not significant. 
Now we can summarize the t-test results for differences in WTP in Table 9. To control for the influence of cost-level smoothing, we present the classic Turnbull WTP and the "fitted" Turnbull WTP. The upper panel shows the results for the test of the presence of hypothetical bias. We find a significant difference in mean WTP for Ind and Coll for both smoothing procedures. For example in Ind, hypothetical fitted $\mathrm{WTP}_{\mathrm{LBT}}$ is $19.13 € / \mathrm{tCO}_{2}$ and real fitted $\mathrm{WTP}_{\mathrm{LBT}}$ is $16.64 € / \mathrm{tCO}_{2}$. The difference is $2.49 €$ and therefore hypothetical WTP is 1.15 times larger than real WTP. For Coll the ratio is 1.20 . The lower panel summarizes the results for the test of the influence of collective decision making. As already demonstrated, the difference between real WTP in Ind and Coll is influenced by the Turnbull smoothing procedure. Therefore we only interpret the fitted Turnbull WTP. There is no influence of collective decision making on mean WTP in REAL (note however that median WTP in REAL_Ind is $22 €-30 €$ and in REAL_Coll median WTP is above 30€), but there is a statistically significant influence of Coll in the HYPO treatment, although the difference is only $1.50 €$.

Table 9: Differences in WTP

\begin{tabular}{|c|c|c|c|c|c|c|c|c|}
\hline & \multicolumn{8}{|c|}{ "Hypothetical decision situation } \\
\hline & \multicolumn{4}{|c|}{ Ind } & \multicolumn{4}{|c|}{ Coll } \\
\hline Treatment & $\begin{array}{l}\text { REAL_ } \\
\text { Ind }\end{array}$ & $\begin{array}{l}\text { HYPO_ } \\
\text { Ind }\end{array}$ & $\begin{array}{c}\mathrm{t}- \\
\text { value }\end{array}$ & $\begin{array}{c}\mathrm{p}- \\
\text { value }\end{array}$ & $\begin{array}{c}\text { REAL_ } \\
\text { Coll }\end{array}$ & $\begin{array}{c}\text { HYPO_ }_{-} \\
\text {Coll }\end{array}$ & $\begin{array}{c}\mathrm{t}- \\
\text { value }\end{array}$ & $\begin{array}{c}\mathrm{p}- \\
\text { value }\end{array}$ \\
\hline Turnbull & 16.15 & 18.77 & & & 13.79 & 18.15 & & \\
\hline WTP & $(0.23)$ & $(0.13)$ & 3.10 & $\mathrm{p}<0.01$ & $(0.10)$ & $(0.06)$ & 10.70 & $\mathrm{p}<0.01$ \\
\hline Fitted Turnbull & 16.64 & 19.13 & & & 17.23 & 20.63 & & \\
\hline \multirow[t]{4}{*}{ WTP } & $(0.17)$ & $(0.08)$ & 4.99 & $\mathrm{p}<0.01$ & $(0.17)$ & $(0.07)$ & 6.90 & $\mathrm{p}<0.01$ \\
\hline & \multicolumn{8}{|c|}{ Collective action } \\
\hline & \multicolumn{4}{|c|}{ REAL } & \multicolumn{4}{|c|}{ HYPO } \\
\hline & $\begin{array}{c}\mathrm{REAL}_{-} \\
\text {Ind }\end{array}$ & $\begin{array}{c}\mathrm{REAL}_{-} \\
\text {Coll }\end{array}$ & $\begin{array}{c}\text { t- } \\
\text { value }\end{array}$ & $\begin{array}{c}\mathrm{p}- \\
\text { value }\end{array}$ & $\begin{array}{c}\mathrm{HYPO}_{-} \\
\text {Ind }\end{array}$ & $\begin{array}{c}\mathrm{HYPO}_{-} \\
\text {Coll }\end{array}$ & $\begin{array}{c}\text { t- } \\
\text { value }\end{array}$ & $\begin{array}{c}\mathrm{p}- \\
\text { value }\end{array}$ \\
\hline Turnbull & 16.15 & 13.79 & & & 18.77 & 18.15 & & \\
\hline WTP & $(0.23)$ & $(0.10)$ & 4.05 & $\mathrm{p}<0.01$ & $(0.13)$ & $(0.06)$ & 1.42 & $\mathrm{p}>0.1$ \\
\hline Fitted Turnbull & 16.64 & 17.23 & & & 19.13 & 20.63 & & \\
\hline WTP & $(0.17)$ & $(0.17)$ & 1.02 & $\mathrm{p}>0.1$ & $(0.08)$ & $(0.07)$ & 3.83 & $\mathrm{p}<0.01$ \\
\hline
\end{tabular}

Notes: Variances in parentheses. P-values are two-sided. 


\subsection{Econometric analyses}

This section presents logit models to estimate treatment and covariate effects on the probability to buy the certificate. Table 10 summarizes the independent variables of the following models. The covariates include standard demographic variables such as gender, age, education and income. Additionally, we test the influence of attitudes towards the environment and climate policies. $71 \%$ of respondents are worried or very worried about global warming. $33 \%$ stated that they deem the EU ETS fit to reduce $\mathrm{CO}_{2}$ emissions, whereas $50 \%$ stated this about the subsidies to promote renewable energies. Almost one third of respondents agree to the statement "It is pointless if I do something against climate change as an individual." We use this statement as a proxy for dilemma awareness, which measures the degree to which the sample is aware of the social dilemma of emission reductions. Dilemma awareness has been found to affect WTP for public goods (Liebe et al. 2011). Finally, we measure the degree of pro-environmental behaviour with the Personal Norm Scale (Stern et al. 1999, Steg et al. 2005, Steg et al. 2013) which explains support for pro-environmental action. The question wording and the scale properties are given in Annex C. 


\begin{tabular}{lccc}
\hline \hline Variable & Mean (SD) & Min & Max \\
\hline Male & 0.51 & 0 & 1 \\
Age & $43(13)$ & 18 & 66 \\
Kids in HH & 0.30 & 0 & 1 \\
Single & 0.40 & 0 & 1 \\
Academic degree & 0.23 & 0 & 1 \\
Green party voter & 0.12 & 0 & 1 \\
HH income & & & \\
$\quad$ 500-1,499 (low) & 0.22 & & \\
1,500-2,999 (middle) & 0.34 & & \\
$\quad 3,000-10,000+($ high and very high) & 0.27 & & \\
$\quad$ Missing & 0.18 & & \\
Worry & 0.71 & 0 & 1 \\
Emission trading & 0.33 & 0 & 1 \\
Renewables & 0.50 & 0 & 1 \\
Dilemma awareness & 0.28 & 0 & 1 \\
Personal norm & $3.12(0.88)$ & 1 & 5 \\
\hline \hline
\end{tabular}

The results for the full models are presented in Table 11. The dependent variable indicates whether a subject chose the certificate over the cash amount. Overall, the logit results confirm the univariate results of the treatment influences. We find no effect of cheap talk, therefore hypothetical treatments with and without cheap talk are pooled together in the following analysis. ${ }^{7}$ We observe hypothetical bias as a significant difference in the probability to buy a certificate between REAL and HYPO and a significant influence of collective decision making in the hypothetical treatment but not in REAL. Columns 1 and 2 present the results for the REAL groups and add an indicator for HYPO. The odds ratio of being in the hypothetical group over being in the REAL group are 1.36, indicating that the odds of buying a certificate are $36 \%$ higher in the hypothetical group. In the collective decision group the odds of choosing the certificate over the cash price are $66 \%$ higher. ${ }^{8}$ Columns 3 and 4 present the results for the hypotheses of the effect of collective decision making. The coefficients for the treatment indicators show that the change to a collective decision framework has no effect on the probability to choose the certificate when real transactions are involved but it does have a positive effect in a hypothetical setting. 
Furthermore, we find evidence for the factors underlying the decision. First, for individual decisions the price of the certificate reduces the odds of buying by $2.7 \%$ for each additional Euro or by $18 \%$ for a standard deviation of $7.49 €\left[100 *\left(e^{\log (0.9734) * 7.49)}-1\right)\right]$. Second, income categories have a positive influence on the decision in the REAL treatments. For example, in the REAL treatments a high income positively correlates with the probability to choose the certificate. The last column, which includes only observations from the HYPO treatments, shows no effect of income. Other demographic variables are mostly insignificant or only significant in one or two of the four regressions.

Table 11: Logistic regressions for treatment effects

\begin{tabular}{lllll}
\hline \hline & \multicolumn{2}{l}{ Hypothetical bias } & \multicolumn{2}{l}{ Collective action } \\
\hline & 1 & 2 & 3 & 4 \\
\cline { 2 - 5 } & Ind & Coll & REAL & HYPO \\
\hline Price (centered at mean 16€) & $0.97^{* * * *}$ & $0.97^{* * *}$ & $0.98^{* * * *}$ & $0.97^{* * * *}$ \\
Male & 0.98 & $0.80^{* *}$ & 0.92 & 0.88 \\
Age & 1.00 & 1.00 & 1.00 & 1.00 \\
Kids in HH & $0.75^{* *}$ & 0.90 & $0.63^{* * *}$ & 0.91 \\
Single & 1.14 & 0.93 & 1.21 & 0.93 \\
University degree & 1.11 & 1.15 & 1.06 & 1.17 \\
Votes Green & $1.45^{* *}$ & 1.13 & 1.08 & $1.37^{* *}$ \\
HH Income & & & & \\
$\quad$ Middle & 0.98 & $1.35^{* *}$ & $1.56^{* *}$ & 0.95 \\
$\quad$ High and very high & 1.36 & 1.16 & $1.65^{* *}$ & 1.09 \\
$\quad$ Missing & $1.44^{* *}$ & 1.26 & $1.87^{* * *}$ & 1.15 \\
Worry & $1.56^{* * *}$ & 1.27 & $1.56^{* * *}$ & $1.35^{* * *}$ \\
Policy preferences & & & & \\
$\quad$ Emission trading & $2.40^{* * *}$ & $2.21^{* * *}$ & $2.21^{* * *}$ & $2.27^{* * *}$ \\
$\quad$ Renewables & $1.53^{* * *}$ & $1.61^{* * *}$ & 1.18 & $1.78^{* * *}$ \\
$\quad$ Trading\#Renewables & $0.40^{* * *}$ & $0.42^{* * *}$ & $0.53^{* * *}$ & $0.38^{* * *}$ \\
Dilemma awareness & $0.70^{* * *}$ & $0.52^{* * *}$ & $0.43^{* * *}$ & $0.74^{* * *}$ \\
Personal norm & $1.25^{* * *}$ & $1.34^{* * *}$ & $1.25^{* * *}$ & $1.33^{* * *}$ \\
HYPO & $1.36^{* * *}$ & $1.66^{* * *}$ & & \\
REAL Coll & & & 1.04 & $1.27^{* * *}$ \\
HYPO Coll & & & & 5865 \\
\hline Observations & 4416 & 4395 & 0.080 & 0.059 \\
Pseudo $R^{2}$ & 0.066 & 0.072 & & \\
\hline \hline
\end{tabular}

Notes: Choice of certificate is the dependent variable, coefficients are presented as odds ratios, $* * p<0.05, * * * p<0.01$, standard errors are corrected for clustered observations. 
Policy preferences are also important for the decision to choose the certificate. Subjects who state that emission trading or renewable energy policy is effective in reducing $\mathrm{CO}_{2}$ emissions have larger probability to choose the certificate. The indicator emission trading takes the value one if subjects think that emission trading is effective. In the presence of the interaction term the coefficient of 2.40 means that subjects who think that emission trading is effective, but renewable energy is not, have (on average) $140 \%$ larger odds to choose the certificate than subjects who believe that neither option is effective. Subjects who believe that emission trading and renewable energy is effective have a $2.40 * 0.40=0.96$ times smaller odds than subjects who believe that only renewable energy is effective and a $1.53 * 0.40=0.57$ times smaller odds than subjects who believe that only emission trading is effective. Believing that only emission trading is effective has therefore the largest effect on the probability to choose the certificate and the stated policy preferences are consistent with the choice of certificates. ${ }^{9}$ The coefficient for dilemma awareness measures the effect of the belief that it makes no sense to reduce reduction, if others are not doing the same. As expected dilemma awareness reduces the probability to choose the certificate. Personal norm is a scale that measures a propensity to act environmentally friendly. Accordingly, the more people state to act environmentally friendly in their daily lives, the larger the probability to choose the certificate. 
Table 12: Average predicted probabilities to buy a certificate

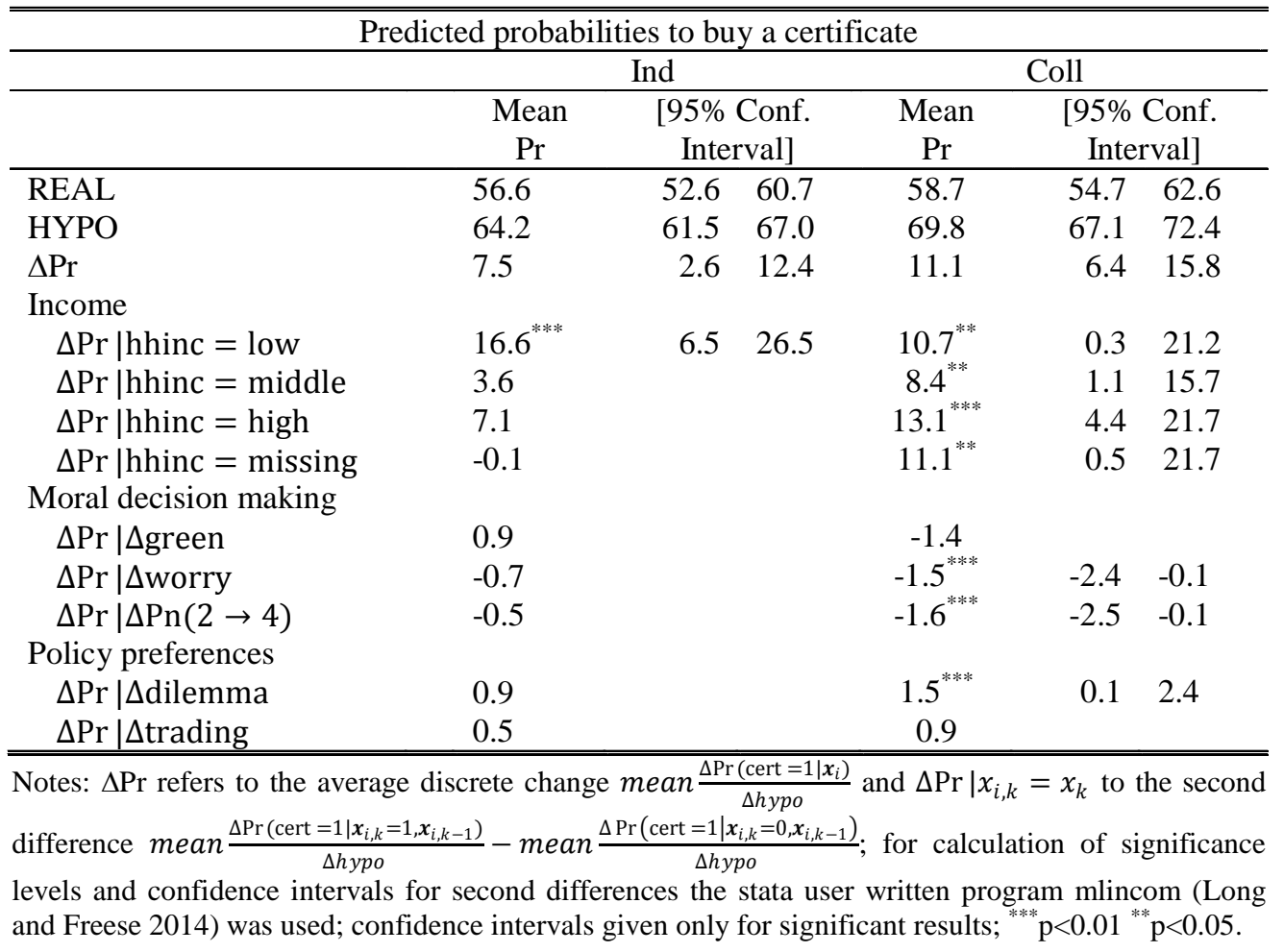

To examine the determinants of hypothetical bias we will discuss results on the probability scale. Table 12 shows that the average probability to buy a certificate is $57 \%$ for REAL and $64 \%$ for HYPO in the Ind group. The difference corresponds to the amount of hypothetical bias in the probability to buy a certificate, which is on 7.5 percentage points in Ind and 11.1 percentage points in Coll, but this change is not significant. Thus, hypothetical bias in terms of probability to buy is 1.13 (Ind) and 1.19 (Coll). The confidence intervals for the differences in probability are, however, quite wide. Table 12 also shows the average marginal effect of HYPO at different levels of income and for different characteristics of respondents. In Ind, hypothetical bias is largest for subjects with low income and not significant for subjects with any other income including missing values, which goes so far, that in a separate regression excluding observations with low incomes eliminates hypothetical bias. ${ }^{10}$ Furthermore other characteristics have no influence on hypothetical bias. However, this does not apply to the 
Coll group where the effect of income on hypothetical bias is constant. People with larger personal norm or who worry about climate change exhibit a smaller bias and people who are aware of the social dilemma aspect of the public good have a larger bias than those who are not.

\section{Conclusion}

This paper investigates factors that affect the voluntary demand for climate change mitigation. Three main potential drivers of the demand are investigated: (i) the framing of the hypothetical decision situation either with or without a cheap talk script, (ii) whether the decision for climate change mitigation causes real monetary costs or not, and (iii) the effect of a collective action on the contribution level of a small group of subjects. As a vehicle to facilitate real contributions to climate change mitigation the EU ETS was used. Our main results can be summarized as follows. We find a significant hypothetical bias in the voluntary demand for climate change mitigation, which in WTP terms is 1.15 (Ind) and 1.20 (Coll). In terms of probability to contribute, hypothetical bias is characterized by a large spread of between 3 and 16 percentage points. Remarkably, the bias for the individual decision treatment is completely caused by subjects with low income, whereas the bias in the collective treatment is explained by additional determinants, such as environmental awareness, which partially corresponds with the analysis of Mjelde et al. (2012), who also found that the environmentally conscious tend to show less bias. Collective action influences voluntary demand for climate change mitigation only in a hypothetical decision situation and not if subjects face real monetary incentives. We do not observe an effect of the cheap talk script.

The observed hypothetical bias is surprisingly small. One potential reason for this result lays in the experimental good employed as vehicle for climate change mitigation. Large hypothetical bias can be observed for goods with a high moral content such as species 
protection (Johansson-Stenman and Svedsäter 2012). EU ETS allowances are a rather abstract good without such a positive reputation. They could have even a negative reputation due to the recent discussions about the effectiveness of the EU ETS (e.g. Koch et al. 2014) and the discussions about tax fraud. ${ }^{11}$ Additionally, Diederich and Goeschl (2014b) demonstrate in a within comparison of contribution choices that project based Certified Emission Reductions (CERs) are favoured over ETS allowances. Thus, our design presumably delivers a "lower bound" for the hypothetical bias of voluntary contribution to climate change mitigation.

Furthermore, our results are related to the literature on the effects of partial collective action on the contributions to public goods. Similarly to these experiments we observe a higher proportion of subjects who contribute to the global public good if a collective action is implemented. However, we observe such a "partial voting effect" (Hauser et al. 2014, Bernard et al. 2013) only when decisions are hypothetical. When subjects face real monetary incentives the effect vanishes. The fact, that we observe a collective action effect only under hypothetical decisions is consistent with economic theory. While in a regular public good setting under collective action full contribution constitutes a payoff-dominant equilibrium, in our global public good setting under partial collective action this is no longer the case. When marginal benefits are zero and marginal costs are positive, the full contribution equilibrium is payoff-dominated by the zero contribution equilibrium and should not be observed.

But again one has to take into account that our good is extremely abstract and probably lacks the positive moral evaluation usually associated with environmental public goods, which could be a reason why other studies find a social context effect in both hypothetical and real settings. For example, Alpizar et al. (2008) find that the influence of social information and anonymity is about the same when subjects make actual monetary contributions as when they state hypothetical contributions. Similarly Mozumder and Berrens (2011) find that the social context effect - voting disclosure - occurs in real and hypothetical settings, but that the 
hypothetical cases are more prone to social context and that the effect is muted by perceived benefits.

Given our surprisingly small hypothetical bias and the collective action effect specific to hypothetical setting, it would be interesting to check whether for goods with different moral content and perceived benefit the bias differs. This could be done by using CER offsets with specific ancillary benefits of climate change mitigation. We leave this question for further research.

\footnotetext{
${ }^{1}$ In this paper, all WTP values are, if necessary, converted to $€$ values using the 2010 ECB average reference exchange rate for US $\$(€ 1=$ US $\$ 1.3257)$ or GBP $(€ 1=$ GBP 0.8578$)$.

${ }^{2}$ For the following hypotheses we use the cheap talk variant of the hypothetical treatment, because for stated preferences applications this is generally considered as the more robust procedure to elicit WTP.

${ }^{3}$ A transaction confirmation is available under https://bsturm.htwk-leipzig.de/uehleke/fairpayclim/

${ }^{4}$ Note that 173 participants ( $5.6 \%$ of the sample) decided inconsistently, because they chose the certificate at a high price, but not at a low price. We did not exclude these participants, since we are interested in the overall behavioural effect. A separate analysis shows that excluding these participants has no effect on the results.
}

${ }^{5}$ The test statistic for the difference in average WTP constitutes $t=\frac{\overline{W T P}_{1}-\overline{W T P}_{2}}{\sqrt{\widehat{\sigma}_{1}^{2}+\widehat{\sigma}_{2}^{2}}}$ (Haab and McConnel 2003, p.76; Carson et al. 2004, p.183).

${ }^{6}$ The WTP calculation with the fitted shares is given in Annex B3.

${ }^{7}$ We repeated the analyses with separate groups which did not change results. Results can be delivered upon request from the corresponding author.

${ }^{8}$ Note that it is not possible to compare effect sizes across different logit models. A test for difference in hypothetical bias between Ind and Coll requires the respective interaction effect, which in a separate regression is not significant. Thus we cannot reject the hypothesis of equal hypothetical bias in Ind and Coll.

${ }^{9}$ We confirmed that the interaction effect is significant for all observations with the stata user written programme inteff (Norton et al. 2004).

${ }^{10}$ Results in Annex D.

11 See for example https://www.europol.europa.eu/content/press/carbon-credit-fraud-causes-more-5-billioneuros-damage-european-taxpayer-1265. 


\section{References}

Aadland D, Caplan AJ (2003) Willingness to Pay for Curbside Recycling with Detection and Mitigation of Hypothetical Bias. AJAE 85(2): 492- 502

Aadland D, Caplan AJ (2006) Cheap Talk Reconsidered: New Evidence from CVM. J Econ Behav Organ 60(4): 562-578

Achtnicht M (2012) German Car Buyers' Willingness to Pay to Reduce $\mathrm{CO}_{2}$ Emissions. Climatic Change 113(3): 679-697

Alpizar F, Carlsson F, Johansson-Stenman O (2008) Does context matter more for hypothetical than for actual contributions? Evidence from a natural field experiment. Exp Econ 11(3): 299-314

Andreoni J (1990) Impure Altruism and Donations to Public Goods: A Theory of Warm Glow Giving. Econ J 100(401): 464-77

Bernard M, Dreber A, Strimling P et al. (2013) The subgroup problem: When can binding voting on extractions from a common pool resource overcome the tragedy of the commons? J Econ Behav Organ 91: 122-130

Blasch J, Farsi M (2014) Retail demand for voluntary carbon - a choice experiment among Swiss consumers. JEEP 3(1): 1-24

Blumenschein K, Blomquist GC, Johannesson M et al. (2008) Eliciting Willingness to Pay Without Bias: Evidence from a Field Experiment. Econ J 118(525): 114-137

Brouwer R, Brander L, Van Beukering P (2008) "A convenient truth": air travel passengers willingness to pay to offset their $\mathrm{CO}_{2}$ emissions, Climatic Change 90(3): 299-313

Brown TC, Ajzen I, Hrubes D (2003) Further Tests of Entreaties to Avoid Hypothetical Bias in Referendum Contingent Valuation. JEEM 46(2): 353-361

Carson RT, Conaway MB, Hanemann WM et al (2004) Valuing Oil Spill Prevention: A Case Study of California's Central Coast. In: Bateman IJ (ed) The Economics of Non-Market Goods and Resources, vol 5. Springer Science + Business Media, BV

Champ PA, Bishop RC, Brown TC et al (1997) Using Donation Mechanisms to Value Nonuse Benefits from Public Goods. JEEM 33(2): 151-162 
Champ PA, Flores NE, Brown TC et al (2002) Contingent Valuation and Incentives. Land Econ 78(4): $591-604$

Champ PA, Moore R, Bishop RC (2009) A Comparison of Approaches to Mitigate Hypothetical Bias. ARER 38(2): 166-180

Cherry TL (2001) Mental accounting and other-regarding behaviour: Evidence from the lab. J Econ Psychol 22(5): 605-615

Cherry TL, Frykblom P, Shogren JF (2002) Hardnose the Dictator. Am Econ Rev 92(4): 1218-1221

Cooper P, Gregory LP, Bateman IJ (2004) The structure of motivation for contingent values: a case study of lake water quality improvement. Ecol Econ 50(1-2): 69-82

Crumpler H, Grossman PJ (2008) An experimental test of warm glow giving. J Public Econ 92(5-6): $1011-1021$

Cummings RG, Harrison GW, Rutström EE (1995) Homegrown Values and Hypothetical Surveys: Is the Dichotomous Choice Approach Incentive-Compatible? Am Econ Rev 85(1): 260-266

Cummings RG, Elliot S, Harrison GW et al (1997) Are Hypothetical Referenda IncentiveCompatible? J Polit Econ 105(3): 609-621

Cummings RG, Taylor LO (1999) Unbiased Value Estimates for Environmental Goods: A Cheap Talk Design for the Contingent Valuation Method. Am Econ Rev 89(3): 649-665

Diederich J, Goeschl T (2014a) Willingness to Pay for Voluntary Climate Action and Its Determinants: Field-Experimental Evidence. ERE 57(3): 405-429

Diederich J, Goeschl T (2014b) Motivational Drivers of the Private Provision of Public Goods: Evidence From a Large Framed Field Experiment. Discussion Paper Series / University of Heidelberg, Department of Economics 0561, urn:nbn:de:bsz:16-heidok-167229

Fischbacher U, Gächter S, Fehr E (2001) Are People Conditionally Cooperative? Evidence from a Public Goods Experiment. Econ Lett 71(3): 397-404

Haab TC, McConnell KE (2003) Valuing Environmental and Natural Resources. The Econometrics of Non-market Valuation, E. Elgar Pub., Cheltenham Northampton

Hauser OP, Rand DG, Peysakhovich A et al (2014) Cooperating with the future. Nature 511: 220-225 
Johansson-Stenman O, Svedsäter H (2010) Self-Image and Valuation of Moral Goods: Stated versus Actual Willingness to Pay. J Econ Behav Organ 84(3): 879-891

Kahneman D, Knetsch JL (1992) Valuing public goods: The purchase of moral satisfaction. JEEM 22(1): $57-70$

Koch N, Fuss S, Grosjean G et al (2014) Causes of the EU ETS price drop: Recession, CDM, renewable policies or a bit of everything? New evidence. Energ Policy 73: 676-685

Kosfeld M, Okada A, Riedl A (2009) Institution formation in public goods games. Am Econ Rev 99(4): 1335-1355

Kroll S, Cherry TL, Shogren JF (2007) Voting, punishment, and public goods. Econ Inq 45(3): 557570

Landry CE, List JA (2007) Using Ex Ante Approaches to Obtain Credible Signals for Value in Contingent Markets: Evidence from the Field. Am J Agr Econ 89(2): 420-429

Liebe U, Preisendörfer P, Meierhoff J (2011) To Pay or Not to Pay: Competing Theories to Explain Individuals' Willingness to Pay for Public Environmental Goods. Environ Behav 43(1): 106130

List JA (2001) Do Explicit Warnings Eliminate the Hypothetical Bias in Elicitation Procedures?

Evidence from Field Auctions for Sportscards. Am Econ Rev 91(5):1498-1507

Long JS, Freese J (2014) Regression Models for Categorical Dependent Variables in Stata. College Station, TX: Stata Press, 3rd ed.

Löschel A, Sturm B, Vogt C (2013) The Demand for Climate Change mitigation - An Empirical Assessment for Germany. Econ Lett 118: 415-418

Löschel A, Sturm B, Uehleke R (2014) Revealed Preferences for Climate Change mitigation when the Purely Individual Perspective is Relaxed - Evidence from a Framed Field Experiment, ZEW Discussion Paper No. 13-006, Mannheim

MacKerron GJ, Egerton C, Gaskell C et al (2009), Willingness to pay for carbon offset certification and co-benefits among (high-)flying young adults in UK. Energ Policy 37(4): 1372-1381

Margreiter M, Sutter M, Dittrich D (2005) Individual and Collective Choice and Voting in Common Pool Resource Problem with Heterogeneous Actors. ERE 32(2): 241-271 
Menges R, Traub S (2009) An Experimental Study on the Gap between Willingness to Pay and Willingness to Donate for Green Electricity. Finanzarchiv/Public Finance Analysis 65(3): 335357

Mjelde JW, Jin YH, Lee C et al (2012) Development of a bias ratio to examine factors influencing hypothetical bias. J Environ Manage 95(1): 39-48

Morrison M, Brown TC (2009) Testing the Effectiveness of Certainty Scales, Cheap Talk, and Dissonance-Minimization in Reducing Hypothetical Bias in Contingent Valuation Studies. ERE 44(3): 307-326

Moser R, Raffaelli R, Notaro S (2014) Testing hypothetical bias with a real choice experiment using respondents' own money. Eur Rev AgricEcon 41(1): 25-46

Mozumder P, Berrens RP (2011) Social context, financial stakes and hypothetical bias: an induced value referendum experiment. Appl Econ 43(29): 4487-4499

Murphy JJ, Allen PG, Stevens TH et al (2005) A Meta-Analysis of Hypothetical Bias in Stated Preference Valuation. ERE 30(3): 313-325

Norton EC, Wang H, Ai C (2004) Computing interaction effects and standard errors in logit and probit models. The Stata Journal 4(2): 154-167

Spash C L (2006) Non-Economic Motivation for Contingent Values: Rights and Attitudinal Beliefs in the Willingness To Pay for Environmental Improvements. Land Econ 82(4): 602-622

Sugden R (1984) Reciprocity: The Supply of Public Goods through Voluntary Contributions. Econ J 94(376): 772-787

Steg L, van den Berg AE, De Groot JIM (2013) Environmental Psychology. An Introduction. Chichester, West Sussex: Wiley-Blackwell

Steg L, Dreijerink L, Abrahamse W (2005) Factors influencing the acceptability of energy policies: A test of VBN theory. J Environ Psychol 25(4): 415-425

Stern PC, Dietz T, Abel T et al (1999) A Value-Belief-Norm Theory of Support for Social Movements: The Case of Environmentalism. Hum Ecol Rev 6(2): 81-97

Taylor LO, Morrison MD, Boyle KJ (2010) Exchange Rules and the Incentive Compatibility of Choice Experiments. ERE 47(2): 197-220 
Walker J, Gardner R, Herr A et al (2000) Collective Choice in the Commons: Experimental Results on Proposed Allocation Rules and Votes. Econ J 110(460): 212-234

Wiser R (2007) Using Contingent Valuation to Explore Willingness to Pay for Renewable Energy: A Comparison of Collective and Voluntary Payment Vehicles. Ecol Econ 62(3/4): 419-432 
Annex A1: Information Screen

\section{Information on the European Emissions Trading System}

The EU Emissions Trading System for carbon dioxide $\left(\mathrm{CO}_{2}\right)$ came into force in 2005. Emission trading is the key instrument of climate policy in Europe, which is based on a simple principle: It is specified how much $\mathrm{CO}_{2}$ the participating sectors (power generators and energy-intensive industries) are allowed to emit until 2020. This total amount is distributed as emission rights from the state (so-called "Certificates") to the companies. For each unit of $\mathrm{CO}_{2}$ emitted, the company must give such a certificate to the state. The certificates can be traded between companies.

For every ton of $\mathrm{CO}_{2}$ that is emitted by a facility, such as a coal power plant, the plant operator has to show appropriate authorization in the form of a certificate. This has an important consequence: If the total quantity of allowances is reduced, then the total emissions must be reduced simply because the plant operators have fewer allowances at their disposal. This means that if a certificate for a ton of $\mathrm{CO}_{2}$ is bought and deleted, the total $\mathrm{CO}_{2}$ emissions are reduced by exactly this one ton.

Emission trading has a central advantage. It ensures that avoidance of $\mathrm{CO}_{2}$ emissions takes place where it is cheapest. Companies with inexpensive ways to avoid $\mathrm{CO}_{2}$ will sell allowances. Companies where avoidance is rather expensive purchase certificates. This trade ensures that the emission target is achieved at minimal cost.

European electricity producers and the energy-intensive industry may emit a total of about 2 billion tons $\mathrm{CO}_{2}$ in 2014. In comparison, the global $\mathrm{CO}_{2}$ emissions in 2013 were approximately 36 billion tons of $\mathrm{CO}_{2}$.

To sum up: If you decrease the total amount of allowances in the EU ETS, European total emissions of $\mathrm{CO}_{2}$ are reduced. 
Annex A2: Instruction screen for the REAL_Ind treatment

\section{Instructions}

\section{Payoff}

You can now choose between a cash payment, and a certificate of one ton of $\mathrm{CO}_{2}$ emissions from the EU Emissions Trading System. The probability that you win and your decisions will be realized is $20 \%$. Therefore, it is in your interest that you make every decision as if your decision would be realized.

Won certificates will be removed permanently from the trade for you by the research team of the Leipzig University of Applied Sciences. Due to the deletion of a certificate, European $\mathrm{CO}_{2}$ emissions will be reduced by one ton.

\section{Decision}

You will have three possibilities to decide between a cash payment and the deletion of a certificate in the following form:

Please choose now between the cash payment or the emissions trading certificate about one ton of $\mathrm{CO}_{2}$ with subsequent deletion.

I would like the ...

() ... €€ Euro cash payment

() ... emissions trading certificate about one ton of $\mathrm{CO}_{2}$

For the winners one the three decisions is randomly selected and depending on how you have chosen in this situation, you receive the cash payout or a certificate that will be deleted for you by the research team.

The winners will be notified by email. A summary of the study and the verification of the amount of deleted certificates will be published on the website of the Faculty of Business Administration of the Leipzig University of Applied Sciences. 
Annex A3: Instruction screen for the REAL_Coll treatment

\section{Instructions}

\section{Payoff}

You can now choose as a group between a cash payment, and a certificate of one ton of $\mathrm{CO}_{2}$ emissions from the EU Emissions Trading System. The probability that your group wins and the decision of your group will be realized is $20 \%$. Therefore, it is in your interest that you make every decision as if you would be realized.

Won certificates will be removed permanently from the trade for you by the research team of the Leipzig University of Applied Sciences. Due to the deletion of a certificate, European $\mathrm{CO}_{2}$ emissions will be reduced by one ton.

\section{Voting}

You can now vote on whether each member of your group receives a cash payment or whether all members receive a certificate for deletion. Your group is composed of 100 participants. If more than half of the participants vote for the cash payment, each participant will receive the cash payment and if more than half of the participants vote for the deletion of a certificate, each participant will receive a certificate for deletion.

You will have three possibilities to decide between a cash payment and the deletion of a certificate in the following form:

Please vote now for the cash payment or for the emissions trading certificate about one ton of $\mathrm{CO}_{2}$ with subsequent deletion.

I vote for ...

() ... €€ Euro cash payment

() ... The emissions trading certificate through a ton of $\mathrm{CO}_{2}$

For the winning group one of the three decisions is randomly chosen and depending on how the group has decided in this situation, you receive the cash payout or a certificate that will be deleted for you by the research team.

The winners will be notified by email. A summary of the study and the verification of the amount of deleted certificates will be published on the website of the Faculty of Business Administration of the Leipzig University of Applied Sciences. 
Annex A4: Cheap talk script

In surveys is often observed that some respondents state to be willing to pay large amounts for environmental goods such as clean air. Probably these respondents do not account in this moment that they would have to dispense with other things, if they had to actually pay he amount of money they stated in the survey. We therefore ask you to decide in the following situations as if your decision would have real consequences, that means as if you actually received either the cash payment or the certificate. The results of the study will be published on the website of the Faculty of Business Administration of the Leipzig University of Applied Sciences.

\section{Annex B1: Calculation of Turnbull WTP}

The lower bound Turnbull is computed in the following steps:

1. Calculate the share of no answers: $\mathrm{F}_{\mathrm{j}}=\mathrm{N}_{\mathrm{j}} / \mathrm{T}_{\mathrm{j}}$

2. Compare $F_{j}$ with $F_{j+1}$, if $F_{j}<F_{j+1}$ continue, if $F_{j}>=F_{j+1}$ these cells are pooled and the combined no shares of these cells calculated: $\mathrm{F}_{\mathrm{j}}{ }^{*}=\mathrm{N}_{\mathrm{j}}{ }^{*} / \mathrm{T}_{\mathrm{j}}{ }^{*}$

3. This is repeated until a monotonously increasing cdf is formed.

4. Calculate $\mathrm{f}_{\mathrm{j}}^{*}=\mathrm{F}_{\mathrm{j}+1}{ }_{-} \mathrm{F}_{\mathrm{j}} *$ for each bid level $\mathrm{t}$. This corresponds to a consistent estimator of the probability that WTP falls between the price $j$ and price $j+1$.

5. Multiply every bid with the according probability that WTP falls between this bid and the next higher bid $\mathrm{t}+1$.

6. Sum over the quantities of step 5 to obtain lower bound Turnbull WTP, which is then: $E_{L B}(W T P)=\sum_{j=0}^{M} t_{j}\left(F_{j+1}^{*}-F_{j}^{*}\right)$, and can be interpreted analogous to the consumer surplus as sum of the marginal value multiplied by the adapted quantitites, or the integer over the quantity of a demand curve (Haab and McConnel 2003).

7. Calculate the variance: $V\left(E_{L B}\right)=\sum_{j=1}^{M^{*}} \frac{F_{j}^{*}\left(1-F_{j}^{*}\right)}{T_{j}^{*}}\left(t_{j}-t_{j-1}\right)^{2}$, where $T_{j}^{*}$ is the common amount of observations of the eventually pooled bid cell. 
Annex B2: Lower Bound Turnbull for REAL_Coll without five observations at bid=30

\begin{tabular}{|c|c|c|c|c|c|c|c|}
\hline$t_{j}$ & $\mathrm{~N}_{\mathrm{j}}$ & $T_{j}$ & $F_{j}$ & $\mathrm{~F}_{\mathrm{j}}{ }^{*}$ & $\mathrm{f}_{\mathrm{j}}^{*}$ & $\mathrm{E}_{\mathrm{LB}}$ & $\mathrm{V}\left(\mathrm{E}_{\mathrm{LB}}\right)$ \\
\hline 2 & 45 & 104 & 0.43 & 0.38 & 0.38 & 0.00 & 0.00 \\
\hline 6 & 33 & 102 & 0.32 & p.b. & & & \\
\hline 8 & 50 & 104 & 0.48 & 0.42 & 0.04 & 0.07 & 0.03 \\
\hline 10 & 41 & 104 & 0.39 & p.b. & & & \\
\hline 12 & 38 & 102 & 0.37 & p.b. & & & \\
\hline 14 & 93 & 209 & 0.44 & 0.42 & 0.01 & 0.05 & 0.02 \\
\hline 16 & 45 & 104 & 0.43 & p.b. & & & \\
\hline 18 & 81 & 206 & 0.39 & p.b. & & & \\
\hline 20 & 45 & 105 & 0.43 & 0.43 & 0.00 & 0.05 & 0.04 \\
\hline 22 & 44 & 104 & 0.42 & p.b. & & & \\
\hline 24 & 50 & 104 & 0.48 & 0.47 & 0.05 & 0.96 & 0.02 \\
\hline 26 & 49 & 105 & 0.47 & p.b. & & & \\
\hline 30 & 47 & 99 & 0.47 & 0.47 & 0.00 & 0.03 & 0.09 \\
\hline 30 & & & & 1.00 & 0.53 & 15.76 & \\
\hline \multicolumn{6}{|c|}{ Lower Bound Turnull: } & 16.92 & 0.20 \\
\hline
\end{tabular}

Annex B3: Turnbull WTP (fitted) for REAL_Ind and REAL_Coll

\begin{tabular}{|c|c|c|c|c|c|c|c|c|c|c|c|c|c|c|}
\hline \multicolumn{8}{|c|}{ Lower Bound Turnbull (fitted) for REAL_Ind } & \multicolumn{7}{|c|}{ Lower Bound Turnbull (fitted) for REAL_Coll } \\
\hline$t_{j}$ & $\mathrm{~N}_{\mathrm{j}}$ & $\mathrm{T}_{\mathrm{j}}$ & $\mathrm{F}_{\mathrm{j}}$ & $\mathrm{F}_{\mathrm{j}}^{\text {fitted }}$ & $\mathrm{f}_{\mathrm{j}}^{\text {fitted }}$ & $\mathrm{E}_{\mathrm{LB}}$ & $\mathrm{V}\left(\mathrm{E}_{\mathrm{LB}}\right)$ & $\mathrm{N}_{\mathrm{j}}$ & $\mathrm{T}_{\mathrm{j}}$ & $\mathrm{F}_{\mathrm{j}}$ & $F_{j}^{\text {fitted }}$ & $\mathrm{f}_{\mathrm{j}}^{\text {fitted }}$ & $\mathrm{E}_{\mathrm{LB}}$ & $\mathrm{V}\left(\mathrm{E}_{\mathrm{LB}}\right)$ \\
\hline 2 & 33 & 101 & 0.33 & 0.34 & 0.34 & 0.00 & 0.01 & 45 & 104 & 0.43 & 0.39 & 0.39 & 0.00 & 0.01 \\
\hline 6 & 39 & 103 & 0.38 & 0.37 & 0.03 & 0.06 & 0.04 & 33 & 102 & 0.32 & 0.40 & 0.01 & 0.02 & 0.04 \\
\hline 8 & 40 & 101 & 0.40 & 0.39 & 0.01 & 0.08 & 0.01 & 50 & 104 & 0.48 & 0.41 & 0.00 & 0.03 & 0.01 \\
\hline 10 & 41 & 105 & 0.39 & 0.40 & 0.01 & 0.11 & 0.01 & 41 & 104 & 0.39 & 0.41 & 0.00 & 0.04 & 0.01 \\
\hline 12 & 46 & 103 & 0.45 & 0.42 & 0.01 & 0.14 & 0.01 & 38 & 102 & 0.37 & 0.42 & 0.00 & 0.05 & 0.01 \\
\hline 14 & 87 & 206 & 0.42 & 0.43 & 0.01 & 0.17 & 0.00 & 93 & 209 & 0.44 & 0.42 & 0.00 & 0.06 & 0.00 \\
\hline 16 & 48 & 105 & 0.46 & 0.44 & 0.01 & 0.20 & 0.01 & 45 & 104 & 0.43 & 0.43 & 0.00 & 0.07 & 0.01 \\
\hline 18 & 96 & 205 & 0.47 & 0.46 & 0.01 & 0.23 & 0.00 & 81 & 206 & 0.39 & 0.43 & 0.00 & 0.08 & 0.00 \\
\hline 20 & 48 & 105 & 0.46 & 0.47 & 0.01 & 0.25 & 0.01 & 45 & 105 & 0.43 & 0.43 & 0.00 & 0.09 & 0.01 \\
\hline 22 & 47 & 105 & 0.45 & 0.49 & 0.01 & 0.28 & 0.01 & 44 & 104 & 0.42 & 0.44 & 0.00 & 0.10 & 0.01 \\
\hline 24 & 56 & 102 & 0.55 & 0.50 & 0.01 & 0.31 & 0.01 & 50 & 104 & 0.48 & 0.44 & 0.00 & 0.11 & 0.01 \\
\hline 26 & 48 & 105 & 0.46 & 0.51 & 0.01 & 0.34 & 0.01 & 49 & 105 & 0.47 & 0.45 & 0.00 & 0.12 & 0.01 \\
\hline 30 & 58 & 102 & 0.57 & 0.54 & 0.03 & 0.73 & 0.04 & 47 & 104 & 0.45 & 0.46 & 0.01 & 0.25 & 0.04 \\
\hline $30+$ & & & 1 & 1 & 0.46 & 13.73 & & & & 1 & 1 & 0.54 & 16.24 & \\
\hline \multicolumn{6}{|c|}{ Lower Bound Turnbull: } & 16.64 & 0.17 & \multicolumn{5}{|c|}{ Lower Bound Turnbull: } & 17.23 & 0.17 \\
\hline
\end{tabular}


Annex C: Covariates for the attitudes towards the environment and climate policies

\begin{tabular}{|c|c|}
\hline Variable & Question wording \\
\hline Worry & Are you generally concerned about global warming or not? \\
\hline Emission & How suitable or unsuitable do you think is the European Emission \\
\hline trading & Trading System for the reduction of $\mathrm{CO}_{2}$ emissions? \\
\hline Renewables & $\begin{array}{l}\text { How suitable or unsuitable do you think are the current subsidies } \\
\text { for the promotion of renewable energies for the reduction of } \mathrm{CO}_{2} \\
\text { emissions? }\end{array}$ \\
\hline $\begin{array}{l}\text { Dilemma } \\
\text { awareness }\end{array}$ & $\begin{array}{l}\text { It is pointless if I do something against climate change as an } \\
\text { individual. }\end{array}$ \\
\hline $\begin{array}{l}\text { Personal } \\
\text { Norm Scale }\end{array}$ & $\begin{array}{l}\text { I don't buy fruit and vegetables from far countries to save } \\
\text { emissions. } \\
\text { I feel obliged to consider the climate impact of my daily activities. } \\
\text { I feel better when I save emissions. } \\
\text { I have a bad conscience when I drive a car instead of using public } \\
\text { transport. } \\
\text { In my daily activities I try to save as many emissions as I can. }\end{array}$ \\
\hline
\end{tabular}

Notes: All question were answered on a five point Likert-scale, the items to measure Personal Norm were summarized in a scale that yielded an alpha value of 0.81 . 
Annex D1: Hypothetical Bias without different income categories (Ind)

\begin{tabular}{|c|c|c|c|c|}
\hline & Inc $\neq$ low & Inc $\neq$ middle & Inc $\neq$ high & Inc $\neq$ missing \\
\hline Price & $0.97^{* * * *}$ & $0.97^{* * * *}$ & $0.97^{* * * * *}$ & $0.98^{* * *}$ \\
\hline Male & 1.03 & 1.00 & 0.90 & 0.98 \\
\hline Age & 1.00 & 1.00 & 1.00 & 1.00 \\
\hline Kids in $\mathrm{HH}$ & 0.78 & $0.71^{* * *}$ & $0.68^{* * *}$ & 0.84 \\
\hline Single & 1.11 & 1.05 & 1.25 & 1.16 \\
\hline University degree & 1.12 & 0.94 & 1.18 & 1.20 \\
\hline Votes Green & $1.52^{* *}$ & 1.13 & 1.48 & $1.67^{* * * *}$ \\
\hline \multicolumn{5}{|l|}{ HH Income } \\
\hline Low & - & Ref & Ref & Ref \\
\hline Middle & Ref & - & 1.04 & 0.96 \\
\hline High and very high & $1.38^{* *}$ & 1.35 & - & 1.34 \\
\hline Missing & $1.49^{* * * *}$ & $1.42^{* *}$ & $1.50^{* *}$ & - \\
\hline Worry & $1.42^{* *}$ & $1.59^{* * * *}$ & $1.54^{* * * *}$ & $1.73^{* * *}$ \\
\hline \multicolumn{5}{|l|}{ Policy preferences } \\
\hline Emission trading & $2.37^{* * *}$ & $2.57^{* * *}$ & $2.90^{* * * *}$ & $2.07^{* * * *}$ \\
\hline Renewables & $1.51^{* * *}$ & $1.65^{* * *}$ & $1.54^{* * *}$ & $1.44^{* * *}$ \\
\hline Trading\#\#Renewables & $0.45^{* * *}$ & $0.35^{\text {**** }}$ & $0.31^{* * *}$ & $0.47^{* * * *}$ \\
\hline Dilemma awareness & $0.71^{* * * *}$ & $0.64^{* * * *}$ & $0.74^{* *}$ & $0.73^{* * * *}$ \\
\hline Personal norm & $1.30^{* * * *}$ & $1.28^{* * * *}$ & $1.28^{* * *}$ & $1.16^{* *}$ \\
\hline HYPO & 1.20 & $1.48^{* * * *}$ & $1.36^{* *}$ & $1.45^{* * *}$ \\
\hline Observations & 3477 & 2907 & 3201 & 3663 \\
\hline Pseudo $R^{2}$ & 0.065 & 0.072 & 0.073 & 0.061 \\
\hline
\end{tabular}

Notes: Choice of certificate is the dependent variable, coefficients are presented as odds ratios, ${ }^{* *} p<0.05, * * * p<0.01$, standard errors are corrected for clustered observations; Ref - Reference Category.

Annex D2: Hypothetical Bias without different income categories (Coll)

\begin{tabular}{llccc}
\hline \hline & Inc $\neq$ low & Inc $\neq$ middle & Inc $\neq$ high & Inc $\neq$ missing \\
\hline Price & $0.97^{* * * *}$ & $0.97^{* * * *}$ & $0.97^{* * * *}$ & $0.97^{* * *}$ \\
Male & $0.72^{* * *}$ & 0.80 & 0.83 & 0.85 \\
Age & 1.01 & 1.00 & 1.00 & 1.00 \\
Kids in HH & 0.90 & 0.82 & 1.00 & 0.91 \\
Single & 1.03 & 0.87 & 1.01 & 0.85 \\
University degree & 1.27 & 1.10 & 1.26 & 1.02 \\
Votes Green & 1.07 & 1.37 & 1.11 & 1.03 \\
HH Income & & & & \\
$\quad$ Low & - & Ref & Ref & Ref \\
$\quad$ Middle & Ref & - & $1.37^{* *}$ & 1.31 \\
$\quad$ High and very high & 0.87 & 1.16 & - & 1.12 \\
$\quad$ Missing & 0.94 & 1.24 & 1.25 & - \\
Worry & 1.25 & 1.29 & 1.13 & $1.42^{* *}$ \\
Policy preferences & & & & \\
$\quad$ Emission trading & $2.46^{* * *}$ & $1.83^{* * *}$ & $2.21^{* * *}$ & $2.42^{* * * *}$ \\
Renewables & $1.62^{* * *}$ & 1.37 & $1.81^{* * *}$ & $1.65^{* * *}$ \\
$\quad$ Trading\#\#Renewables & $0.40^{* * *}$ & $0.54^{* *}$ & $0.36^{* * *}$ & $0.39^{* * *}$ \\
Dilemma awareness & $0.51^{* * *}$ & $0.57^{* * *}$ & $0.54^{* * *}$ & $0.47^{* * *}$ \\
Personal norm & $1.41^{* * *}$ & $1.27^{* * *}$ & $1.43^{* * *}$ & $1.28^{* * *}$ \\
HYPO & $1.67^{* * *}$ & $1.74^{* * *}$ & $1.59^{* * * *}$ & $1.66^{* * *}$ \\
\hline Observations & 3477 & 2889 & 3168 & 3651 \\
Pseudo $R^{2}$ & 0.082 & 0.063 & 0.072 & 0.077 \\
\hline \hline
\end{tabular}

Notes: Choice of certificate is the dependent variable, coefficients are presented as odds ratios, $* * p<0.05, * * * p<0.01$, standard errors are corrected for clustered observations; Ref - Reference Category. 